\title{
Susceptibilidad antimicrobiana de estafilococos aislados en piodermas de caninos de Coro, Venezuela
}

\author{
Antimicrobial susceptibility of staphylococci isolated in canine pyoderma \\ in Coro, Venezuela \\ Glenda Monzant López ${ }^{1}$, Victor Chávez Oberto ${ }^{2,3}$, Lilia Carrero Portillo ${ }^{4,5,6}$
}

\section{Resumen}

Esta investigación retrospectiva estuvo enfocada en el estudio de la etiología de la pioderma en caninos de la ciudad de Coro (estado Falcón, Venezuela), entre 2010 y 2014 , así como del perfil de susceptibilidad a antimicrobianos de las bacterias estafilocócicas. El microorganismo aislado en mayor frecuencia fue Staphylococcus (pseud)intermedius, seguido de Staphylococcus aureus y otras especies. Adicionalmente, se detectaron varios aislados multirresistentes para las dos especies mencionadas, los cuales no se correlacionaron con casos de pioderma recidivante. No se detectó asociación significativa entre la pioderma recurrente y factores de riesgo como el patrón racial, sexo, estrato etario y especie bacteriana infectante. En general, las especies estafilocócicas aisladas mostraron de manera significativa $(\mathrm{p}<0.05)$ susceptibilidad a carbapenémicos, aminoglucósidos y fluoroquinolonas, y resistencia a penicilinas, ciclinas, inhibidores de la síntesis de folatos y polipéptidos.

Palabras clave: Staphylococcus pseudintermedius; pioderma canino; MDR; XDR; SARM; SPRM; SPSM

${ }^{1}$ Postgrado en Sanidad Animal, Área de Postgrado, Universidad Nacional Experimental «Francisco de Miranda», Coro, Venezuela

${ }^{2}$ Programa de Doctorado en Medicina Veterinaria, Facultad de Medicina Veterinaria, Universidad del Zulia, Maracaibo, Venezuela

${ }^{3}$ Laboratorio de Patología y Terapéutica Quirúrgica, Universidad Nacional Experimental «Francisco de Miranda», Coro, Venezuela

${ }^{4}$ Programa de Doctorado en Microbiología, Centro de Estudios Avanzados, Instituto Venezolano de Investigaciones Cientificas, Caracas, Venezuela

${ }^{5}$ Laboratorio de Microbiología Veterinaria, Universidad Nacional Experimental «Francisco de Miranda», Coro, Venezuela

${ }^{6}$ E-mail: llcarrerop@correo.unefm.edu.ve

Recibido: 7 de mayo de 2018

Aceptado para publicación: 26 de diciembre de 2018 
This retrospective investigation was focused on the study of the etiology of pyoderma in canines from the city of Coro (Falcón state, Venezuela), between 2010 and 2014, as well as the profile of antimicrobial susceptibility of staphylococcal bacteria. The most frequently isolated microorganism was Staphylococcus (pseud)intermedius, followed by Staphylococcus aureus and other species. Additionally, several multi-resistant isolates were detected for the two species mentioned, which did not correlate with cases of recurrent pyoderma. No significant association was detected between the recurrent pyoderma and risk factors such as the racial pattern, sex, age and infecting bacterial species. In general, isolated staphylococcal species showed significant $(\mathrm{p}<0.05)$ susceptibility to carbapenems, aminoglycosides and fluoroquinolones, and resistance to penicillin, cyclins, inhibitors of folate synthesis and polypeptides.

Key words: Staphylococcus pseudintermedius; canine pyoderma; MDR; XDR; MRSA; MRSP; MSSP

\section{INTRODUCCIÓN}

La pioderma superficial es una forma clínica de la dermatitis bacteriana y uno de los problemas dermatológicos más comunes (Ihrke, 2000; Pianta et al., 2006; Medleau y Hnilica, 2007). Es considerada una afección secundaria a causas subyacentes (alergias y enfermedades endocrinas), las cuales condicionan una pérdida del equilibrio de la microbiota de la piel (Hensel et al., 2015), dando oportunidad a los patógenos oportunistas para provocar la infección (Antúnez et al., 2009), cuya colonización es a su vez dependiente de sus factores de virulencia (Forsythe et al., 2002, Romero, 2007).

Dentro de la flora microbiana saprófita de la piel se incluyen a los estafilococos, que a su vez se les considera como los principales patógenos de las infecciones bacterianas (Nesbitt y Ackerman, 2001). En el pioderma canino, Staphylococcus intermedius (pseudintermedius) es la bacteria más frecuente (Duquette y Nuttall, 2004; Beça et al., 2015; Ventrella et al., 2017; Worthing et $a l ., 2018)$. Este taxón ha sido revisado y algunos aislados, especialmente los vinculados con dermatitis canina, se han propuesto reclasificar como Staphylococcus pseudintermedius (Braga et al., 2015; Limbago, 2016). Esta bacteria, junto con $S$. intermedius y Staphylococcus delphini, forman el grupo de S. intermedius (GSI), dentro del cual solo es posible diferenciarlas con métodos genotípicos y proteómicos (Kadlec y Schwarz, 2012; Braga et al., 2015; Vigo et al., 2015).

No es frecuente la prescripción de estudios microbiológicos para el abordaje clínico del pioderma canino (Hensel et al., 2015; Guardabassi et al., 2017), por lo que el diseño de la antibioticoterapia es de carácter empírico, basado en los fármacos con conocida eficacia sobre los estafilococos; empero, se corre el riesgo de utilizar aquellos que favorezcan la resistencia, de allí que la implementación de esta herramienta diagnóstica es recomendable en casos particulares (Cain, 2013; Hensel et al., 2015; Guardabassi et al., 2017). Por otro lado, la respuesta a los tratamientos varía especialmente cuando en el proceso infeccioso están involucradas cepas resistentes a la meticilina como las de Staphylococcus aureus (SARM) y $S$. pseudintermedius (SPRM), de las cuales ya se tienen reportes de afecciones en animales (Morris et al., 2006; Van Duijkeren et al., 2011; Frank y Loeffler, 2012; 
Beça et al., 2015), incluyendo dermatitis en caninos con resistencia a penicilina (Antúnez et al., 2009), meticilina (Bourguignon et al., 2016) y hasta multirresistentes (Abusleme, 2009; dos Santos et al., 2016), por lo que la generación de información adecuada a los contextos espacio-temporales sería de utilidad para orientar a los practicantes de la clínica veterinaria en pequeños animales.

Por otra parte, el papel de caninos y felinos en la diseminación de la resistencia antimicrobiana se ha subestimado cuando se les compara con las especies pecuarias. Se evidencia un marcado contraste en las políticas del uso de antimicrobianos entre estos dos grupos; sin embargo la información en los primeros es necesaria para guiar políticas en el uso de estos fármacos en la práctica veterinaria, así como para disminuir los riesgos de transmisión zoonótica (Guardabassi et al., 2004), especialmente ante la creciente frecuencia de aislados multirresistentes en clínica veterinaria (Cain, 2013) y la facilidad de la transmisión horizontal de genes (Duquette y Nuttall, 2004).

Ante el escenario descrito, la presente investigación tuvo como objetivo registrar la frecuencia de estafilococos causales de pioderma canino en Coro (estado Falcón, Venezuela), así como el perfil de susceptibilidad antimicrobiana, para generar información útil para el diseño de tratamientos empíricos y los programas de vigilancia epidemiológica (OIE, 2015c).

\section{Materiales y MéTodos}

La presente investigación fue de carácter exploratorio-observacional (Hernández et al., 2014) y transversal (Peacock J y Peacock $P, 2011)$. Se recolectaron datos a partir de historias clínicas y reportes microbiológicos de 45 caninos atendidos en tres clínicas veterinarias de la ciudad de Coro, Venezuela, entre los meses de abril de 2010 a 2014 (Cuadro 1), los cuales fueron seleccionados de manera no probabilística, debido al previo requerimiento de la anuencia del propietario.

En los casos donde se evidenciaron manifestaciones de dermatitis durante el examen clínico se tomaron datos del historial (raza, edad, sexo y condiciones previas de pioderma recidivante). Se realizó asepsia del sitio de toma de muestra mediante rasurado y desinfección utilizando gasa impregnada en solución salina fisiológica estéril, con drenaje sostenido en caso de presencia de abscesos. El material biológico fue captado con hisopo estéril y preservado en medio de transporte Stuart (Culturette ${ }^{\circledR}$ ), para su envío al laboratorio dentro de las 24 horas (Kwochka, 1996; Ospina, 2016).

Las muestras fueron analizadas en tres laboratorios para el aislamiento e identificación de los microorganismos por métodos fenotípicos (MacFaddin, 1990; Koneman et al., 1999), usando pruebas como tinción de Gram, catalasa, oxidasa, producción de hemolisinas, pigmentos y coagulasa, fermentación de carbohidratos (maltosa, glucosa y manitol), reducción de nitratos, prueba de Vogues-Proskauer y sensibilidad a novobiocina (Kloos y Jorgensen, 1985; MacFaddin, 1990; Koneman et al., 1999; De la Fuente y Orlen, 2002; CLSI, 2018b).

Los ensayos de susceptibilidad antimicrobiana se realizaron por el método de KirbyBauer según las recomendaciones del Clinical and Laboratory Standards Institute (CLSI, 2006a,b, 2011; OIE, 2012b, 2015b) (35 muestras) o por el método de microdilución para determinación de la Concentración Inhibitoria Mínima (CIM) (CLSI, 2011; OIE, 2012b) (10 especímenes).

La selección de los fármacos de prueba se realizó siguiendo las pautas del CLSI para estafilococos (CLSI, 2006b, 2011) y de acuerdo con la disponibilidad en los laboratorios. También se incluyeron algunos antimicrobianos disponibles en la farmacopea veterinaria, o por su utilidad para la identificación de estafilococos (OIE, 2012a,b, 2015a; CLSI, 2018b). 
Cuadro 1. Datos generales del muestreo poblacional

\begin{tabular}{|c|c|c|c|c|c|}
\hline \multirow{2}{*}{$\begin{array}{c}\text { Identificación } \\
\text { del centro } \\
\text { clínico } \\
\text { veterinario } \\
\end{array}$} & \multirow{2}{*}{$\begin{array}{l}\text { Estrato etario } \\
\text { de los } \\
\text { animales }\end{array}$} & \multicolumn{2}{|c|}{ Sexo (patrón racial) } & \multicolumn{2}{|c|}{ Total de caninos } \\
\hline & & Machos & Hembras & $\begin{array}{c}\text { Estrato } \\
\text { etario }\end{array}$ & $\begin{array}{l}\text { Centro } \\
\text { clínico }\end{array}$ \\
\hline \multirow[t]{3}{*}{ A } & Cachorros & 1 (GR) & $1(\mathrm{MN})$ & 2 & 15 \\
\hline & Adultos & $4(3 \mathrm{PC}, 1 \mathrm{Po})$ & $\begin{array}{l}5(1 \mathrm{PBT}, 1 \mathrm{PA}, \\
3 \mathrm{Po})\end{array}$ & 9 & \\
\hline & Gerontes & $1(\mathrm{HS})$ & $\begin{array}{l}3(1 \mathrm{Po}, 1 \mathrm{SP}, 1 \\
\mathrm{Pi})\end{array}$ & 4 & \\
\hline \multirow[t]{3}{*}{ B } & Cachorros & $1(\mathrm{PC})$ & 0 & 1 & 13 \\
\hline & Adultos & $\begin{array}{l}3(1 \mathrm{SP}, 1 \mathrm{~B}, 1 \\
\mathrm{GR})\end{array}$ & $2(1 \mathrm{Pi}, 1 \mathrm{HS})$ & 5 & \\
\hline & Gerontes & $\begin{array}{l}3(1 \mathrm{Po}, 1 \mathrm{~T}, 1 \\
\mathrm{PA})\end{array}$ & $\begin{array}{l}4(2 \mathrm{Po}, 1 \mathrm{PC}, 1 \\
\mathrm{CS})\end{array}$ & 7 & \\
\hline \multirow[t]{3}{*}{$\mathrm{C}$} & Cachorros & $\begin{array}{l}2 \text { (1 BDI, } 1 \\
\text { HS) }\end{array}$ & $2(1 \mathrm{SP}, 1 \mathrm{YT})$ & 4 & 17 \\
\hline & Adultos & $2(1 \mathrm{C}, 1 \mathrm{~B})$ & $\begin{array}{l}4(1 \mathrm{PC}, 1 \mathrm{PM}, \\
1 \mathrm{Po}, 1 \mathrm{PBT})\end{array}$ & 6 & \\
\hline & Gerontes & $\begin{array}{l}3(2 \mathrm{Po}, 1 \\
\text { PMT) }\end{array}$ & $\begin{array}{l}4(2 \mathrm{Po}, 1 \mathrm{~B}, 1 \\
\mathrm{Pi})\end{array}$ & 7 & \\
\hline Totales & & 20 & 25 & & \\
\hline
\end{tabular}

YT, Yorkshire Terrier; T, Teckel; SP, Shar-Pei; PC, Pug Carlino; PMT, Poodle Mini Toy; PM, Poodle mestizo; Po, Poodle; PBT, Pit Bull Terrier; Pi, Pinscher; PA, Pastor Alemán; MN, Mastín Napolitano; HS, Husky Siberiano; GR, Golden Retriever; CS, Cocker Spaniel; C, Chihuahua; BDI, Bull Dog Inglés; B, Bóxer cachorros: 0 a 12 meses; adultos: 13 meses a 6 años; gerontes: mayores de 7 años

Los resultados de los ensayos de susceptibilidad se categorizaron como Sensibles (S), Intermedios (I) o Resistentes (R) según las Tablas CLSI (CLSI, 2006b, 2011). Los resultados en el caso de las evaluaciones de los aislados de $S$. (pseud)intermedius frente a oxacilina (Oxa) y cefoxitin (Cfx) fueron reinterpretados en consideración de las nuevas recomendaciones del CLSI (Wu et al., 2016; CLSI, 2018a).

La clasificación de los microorganismos como multirresistentes (MDR: no susceptibilidad adquirida para al menos un agente en tres o más categorías de antimicrobianos) y extensivamente resistentes (XDR: no suscep- tibilidad para al menos un agente en todas, excepto dos o menos categorías de antimicrobianos; es decir, la bacteria es sensible para solo una o dos categorías) se realizó de acuerdo con el criterio de Magiorakos et al. (2012). Este sistema ha sido aplicado para el estudio de estafilococos aislados de animales (Worthing et al., 2018).

La estimación de la diferencia de proporciones entre los registros de aislamientos se realizó con la prueba de Fisher (Di Rienzo et al., 2005; Balzarini et al., 2008), usando el paquete estadístico InfoStat v. 2016e. Las variables cualitativas fueron analizadas mediante pruebas de estadística inferencial no 
paramétrica (Chi cuadrado de Pearson y odds ratio) (Cerda et al., 2013), considerando una significancia de $\mathrm{p}<0.05$, utilizando los programas SPSS v. 22 y EPI INFO v. 7.

\section{Resultados}

Se aislaron 45 especímenes de estafilococos, siendo $S$. (pseud)intermedius el más frecuente $(\mathrm{n}=23,51.1 \%)$, seguido de $S$. aureus $(\mathrm{n}=16,35.6 \%)$, estafilococos coagulasa negativo (ECN, $n=3,6.7 \%$ ), Staphylococcus haemolyticus $(\mathrm{n}=2,4.4 \%)$ $\mathrm{y}$ otra especie no identificada $(\mathrm{n}=1,2.2 \%)$. Las dos primeras especies alcanzaron en conjunto una frecuencia superior al resto de los aislamientos $(\mathrm{p}<0.05)$. En dos casos se diagnosticaron infecciones mixtas con bacterias de otros géneros, $y$ en otros dos se registraron cultivos negativos.

El 80\% de los eventos correspondieron a recidivas clínicas de dermatitis (36/45), y el agente etiológico en la mayoría fue nuevamente $S$. (pseud)intermedius $(\mathrm{n}=20$, $55.6 \%)$, seguido de $S$. aureus ( $\mathrm{n}=12,33.3 \%$ ), sin asociación significativa entre estas especies con las recidivas.

El Cuadro 2 presenta los hallazgos de acuerdo con los antimicrobianos evaluados, resaltando que en el $66.2 \%$ de las evaluaciones se detectó susceptibilidad. Al clasificar los resultados para todos los aislados de acuerdo con las familias de antimicrobianos, se puede apreciar que los carbapenémicos (93.5\%), aminoglucósidos $(79.4 \%)$ y fluoroquinolonas $(71.8 \%)$ tuvieron mayores registros relativos de $\mathrm{S}$, con cifras de $\mathrm{OR}<1$ $(p<0.05)$. En contraparte, para las penicilinas, ciclinas, inhibidores de síntesis de folatos y polipéptidos se encontraron porcentajes de susceptibilidad cercanos al $50 \%$, por lo que para estos compuestos se predice mayor riesgo de resistencia in vitro; sin embargo, el examen de los registros del Cuadro 2 permite detectar casos puntuales de algunos compuestos (AmC, SAM, PiT, Dox y Min), donde se detecta una susceptibilidad $\geq 50 \%$.
Para el resto de los antimicrobianos evaluados (Tei, Lnz, Nov, QD, Rif, Clor, Nit, lincosamidas, macrólidos, cefalosporinas e inhibidores de $\beta$-lactamasas), al analizarlos de forma agrupada, no se encontró significancia de la susceptibilidad.

La Figura 1 ilustra los resultados para los 23 aislados de $S$. (pseud)intermedius, observándose susceptibilidad $(70 \%)$ en la mayoría de los ensayos. El análisis generalizado por grupos permitió detectar frecuencias significativas $(p<0.05)$ de no susceptibilidad (R e I) para inhibidores de síntesis de folatos, cefalosporinas y ciclinas; sin embargo, para el último grupo se encuentran ejemplos puntuales de antibióticos con eficacia (Dox y Min). Para el resto de los antimicrobianos (Tei, Lnz, Bac, QD, Clor, Nit, lincosamidas, fluoroquinolonas, macrólidos, aminoglucósidos, carbapenémicos, $\beta$ lactámicos/inhibidores de $\beta$-lactamasas y penicilinas), no se encontró asociación con los porcentajes de susceptibilidad para $S$. (pseud)intermedius.

Se registraron dos cepas XDR (8.7\%), ambas con resistencia a Oxa (Wu et al., 2016; CLSI, 2018a) y 7 MDR (30.4\%) de $S$. (pseud)intermedius (Figura 2). De estas, en una se predice la producción de proteínas de unión a penicilina (PBP2) mediante la resistencia a Oxa (Wu et al., 2016; CLSI, 2018a; Worthing et al., 2018), dado que en el resto de los aislamientos $(\mathrm{n}=6)$, si bien no se evaluó este mecanismo de resistencia (CLSI, 2018a), no se detectó susceptibilidad a otros antimicrobianos (Magiorakos et al., 2012) como Tet, Sxt, Rif, Gen, Eri, Clin, Cip, Clor y Amk.

Cerca del $59.7 \%$ de los ensayos realizados a los 16 aislados de $S$. aureus presentaron S (Figura 3). En general, se aprecia sensibilidad a aminoglucósidos y carbapenémicos $(\mathrm{p}<0.05)$, mientras que para cefalosporinas, penicilinas, inhibidores de síntesis de folatos y ciclinas la susceptibilidad fue significativamente menor $(p<0.05)$. No se encontró asociación significativa con los porcenta- 
Cuadro 2. Resultados de pruebas de susceptibilidad antimicrobiana de muestras de pioderma canino

\begin{tabular}{|c|c|c|c|c|c|c|}
\hline \multirow{2}{*}{$\begin{array}{l}\text { Familia de } \\
\text { antimicrobianos }\end{array}$} & \multirow{2}{*}{ Subclase } & \multirow{2}{*}{ Antibiótico } & \multicolumn{4}{|c|}{ Resultados } \\
\hline & & & $\mathrm{S}$ & I & $\mathrm{R}$ & Total \\
\hline \multirow[t]{3}{*}{ Penicilinas $^{\mathrm{a}}$} & Penicilinas & Penicilina $(\mathrm{P})$ & & & 1 & 1 \\
\hline & & Oxacilina (Oxa) ${ }^{a *}$ & 8 & & 9 & 17 \\
\hline & Aminopenicilinas & Ampicilina (Amp) & 7 & 1 & 6 & 14 \\
\hline \multirow{3}{*}{\multicolumn{2}{|c|}{$\begin{array}{l}\text { ß-lactámicos / Inhibidores de } \beta \\
\text { lactamasas }^{\mathrm{a}}\end{array}$}} & $\begin{array}{l}\text { Amoxicilina-Ácido clavulánico } \\
(\mathrm{AmC})^{\mathrm{a}}\end{array}$ & 4 & & 2 & 6 \\
\hline & & Ampicilina-Sulbactam (SAM) & 12 & 1 & 5 & 18 \\
\hline & & Piperacilina-Tazobactam (PiT) & 11 & & & 11 \\
\hline \multirow[t]{9}{*}{ Cefalosporinas $^{\mathrm{a}}$} & $1^{\text {era }}$ generación & Cefalotina $(\mathrm{Cef})^{\mathrm{a}}$ & & & 2 & 2 \\
\hline & $2^{\text {da }}$ generación & Cefuroxime (Cxm) & 3 & 1 & 2 & 6 \\
\hline & $3^{\text {ra }}$ generación & Cefotaxime (Ctx) & 3 & 4 & 11 & 18 \\
\hline & & Ceftriaxone (Cro) ${ }^{\mathrm{a}}$ & 8 & 2 & 4 & 14 \\
\hline & & Ceftibuten $(\mathrm{Cfb})$ & 3 & & 1 & 4 \\
\hline & & Ceftazidime (Czm) & 4 & & & 4 \\
\hline & & Cefoperazona (Cfp) & 7 & 2 & 2 & 11 \\
\hline & $4^{\text {ta }}$ generación & Cefepime $(\mathrm{Cpm})$ & 15 & 4 & 2 & 21 \\
\hline & Cefamicinas & Cefoxitin $(\mathrm{Cfx})^{\mathrm{a} *}$ & 8 & 1 & 8 & 17 \\
\hline \multirow[t]{3}{*}{ Carbapenémicos } & & Ertapenem (Ert) & 3 & & & 3 \\
\hline & & Imipenem (Imp) & 24 & 1 & 2 & 27 \\
\hline & & Meropenem (Mer) & 16 & & & 16 \\
\hline Glicopéptidos & & Teicoplanina (Tei) ${ }^{*}$ & 6 & & & 6 \\
\hline \multirow[t]{5}{*}{ Aminoglucósidos } & & Neomicina (Neo) & & & 1 & 1 \\
\hline & & Gentamicina $(\text { Gen })^{a^{*}}$ & 26 & 1 & 7 & 34 \\
\hline & & Amikacina (Amk) & 15 & 1 & 2 & 18 \\
\hline & & Netilmicina (Net) & 12 & 2 & & 14 \\
\hline & & Tobramicina (Tob) & 1 & & & 1 \\
\hline \multirow[t]{2}{*}{ Macrólidos } & & Azitromicina (Azt) & 2 & & 1 & 3 \\
\hline & & Eritromicina (Eri) ${ }^{a^{*}}$ & 6 & & 5 & 11 \\
\hline \multirow[t]{4}{*}{ Ciclinas } & Glicilciclinas & Tigueciclina (Tig) ${ }^{*}$ & 2 & & 2 & 4 \\
\hline & Tetraciclinas & Tetraciclina (Tet) ${ }^{\mathrm{a}^{*}}$ & 4 & 1 & 12 & 17 \\
\hline & & Doxiciclina (Dox) ${ }^{*}$ & 3 & & & 3 \\
\hline & & Minociclina (Min) ${ }^{*}$ & 1 & & & 1 \\
\hline \multirow{6}{*}{\multicolumn{2}{|c|}{ Fluoroquinolonas }} & Ciprofloxacina (Cip) ${ }^{a^{*}}$ & 27 & 6 & 7 & 40 \\
\hline & & Levofloxacina (Lev) & 18 & 1 & & 19 \\
\hline & & Ofloxacina (Ofx) & 11 & 1 & 3 & 15 \\
\hline & & Moxifloxacina $(\operatorname{Mox})^{a^{*}}$ & 6 & & & 6 \\
\hline & & Lomefloxacina (Lom) & 16 & 4 & 9 & 29 \\
\hline & & Norfloxacina (Nor) & 1 & & & 1 \\
\hline Nitrofuronas & & Nitrofurantoína (Nit) & 4 & & & 4 \\
\hline \multirow{2}{*}{\multicolumn{2}{|c|}{ Lincosamidas }} & Clindamicina $(\mathrm{Clin})^{\mathrm{a}^{*}}$ & 11 & 1 & 4 & 16 \\
\hline & & Lincomicina (Linc) & & & 1 & 1 \\
\hline \multirow{2}{*}{\multicolumn{2}{|c|}{ Inhibidores de síntesis de folatos }} & $\begin{array}{l}\text { Trimetoprim/Sulfametoxazol } \\
(\mathrm{SxT})^{\mathrm{a}^{*}}\end{array}$ & 5 & & 11 & 16 \\
\hline & & Trimetoprim (Trm) & 1 & 1 & 3 & 5 \\
\hline \multicolumn{2}{|l|}{ Fenicoles } & Cloranfenicol (Clor) ${ }^{\mathrm{a}^{*}}$ & 4 & & 4 & 8 \\
\hline \multicolumn{2}{|l|}{ Ansamicinas } & Rifampicina (Rif) ${ }^{a^{*}}$ & 9 & 1 & 3 & 13 \\
\hline \multicolumn{2}{|l|}{ Estreptograminas } & Quinupristin/Dalfopristin (QD) ${ }^{*}$ & 6 & & & 6 \\
\hline \multicolumn{2}{|l|}{ Polipéptidos } & Bacitracina (Bac) & 2 & & 6 & 8 \\
\hline \multicolumn{2}{|l|}{ Oxazolidinona } & Linezolid (Lnz) ${ }^{*}$ & 6 & & & 6 \\
\hline \multicolumn{2}{|l|}{ Aminocumarinas } & Novobiocina (Nov) & 1 & & & 1 \\
\hline \multicolumn{3}{|l|}{ Total } & 342 & 37 & 138 & 517 \\
\hline
\end{tabular}

$\mathrm{S}=$ susceptible, $\mathrm{I}=$ intermedio, $\mathrm{R}=$ resistente; ${ }^{*}=$ recomendados por Magiorakos et al. (2012) para $S$. aureus; $^{\text {a }}=$ evaluados por Worthing et al. (2018) en su trabajo con S. pseudintermedius 


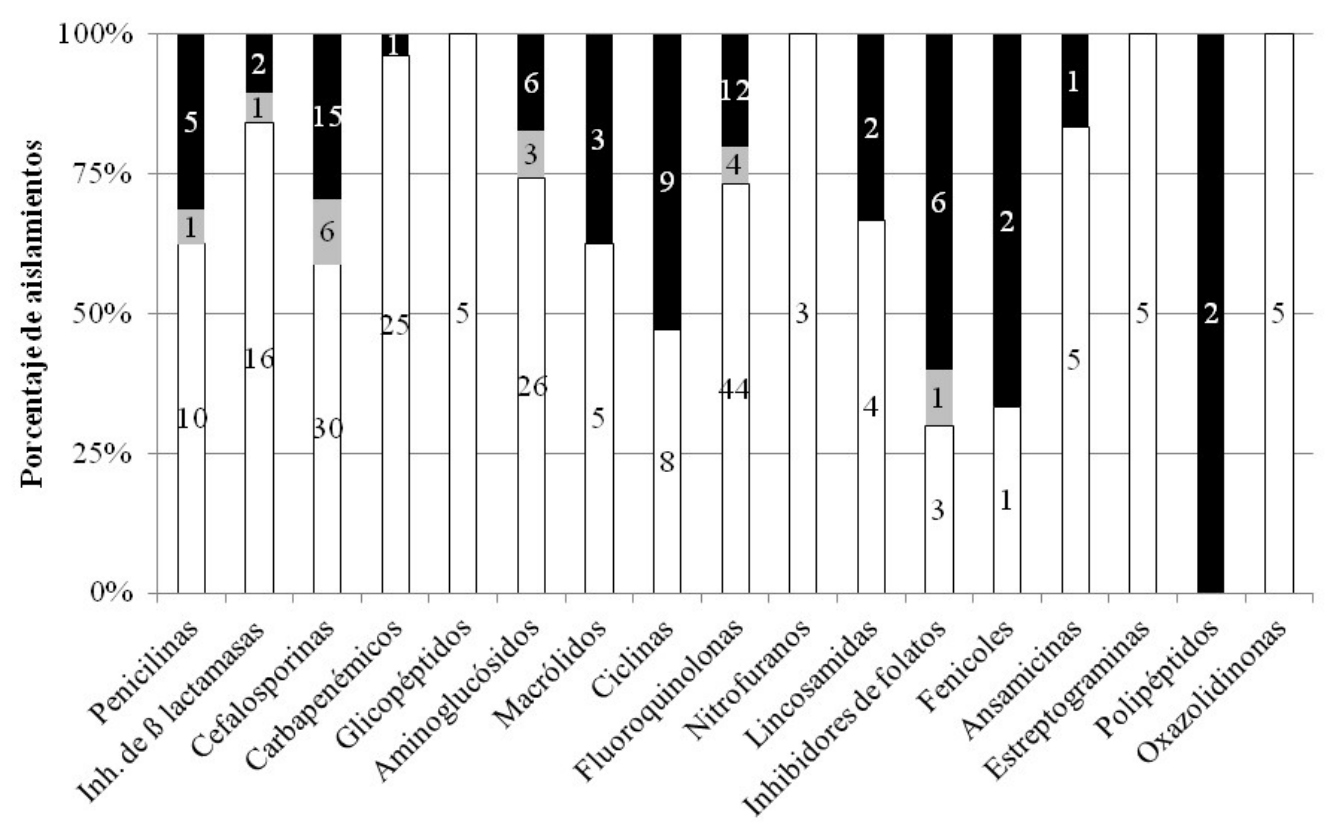

Familias de antimicrobianos

$\square$ Susceptibles $\square$ Intermedios $\square$ Resistentes

Figura 1. Susceptibilidad de aislados de Staphylococcus (pseud)intermedius frente a diversas familias de antimicrobianos. Números dentro de barras indican frecuencias absolutas, eje vertical señala frecuencia relativa

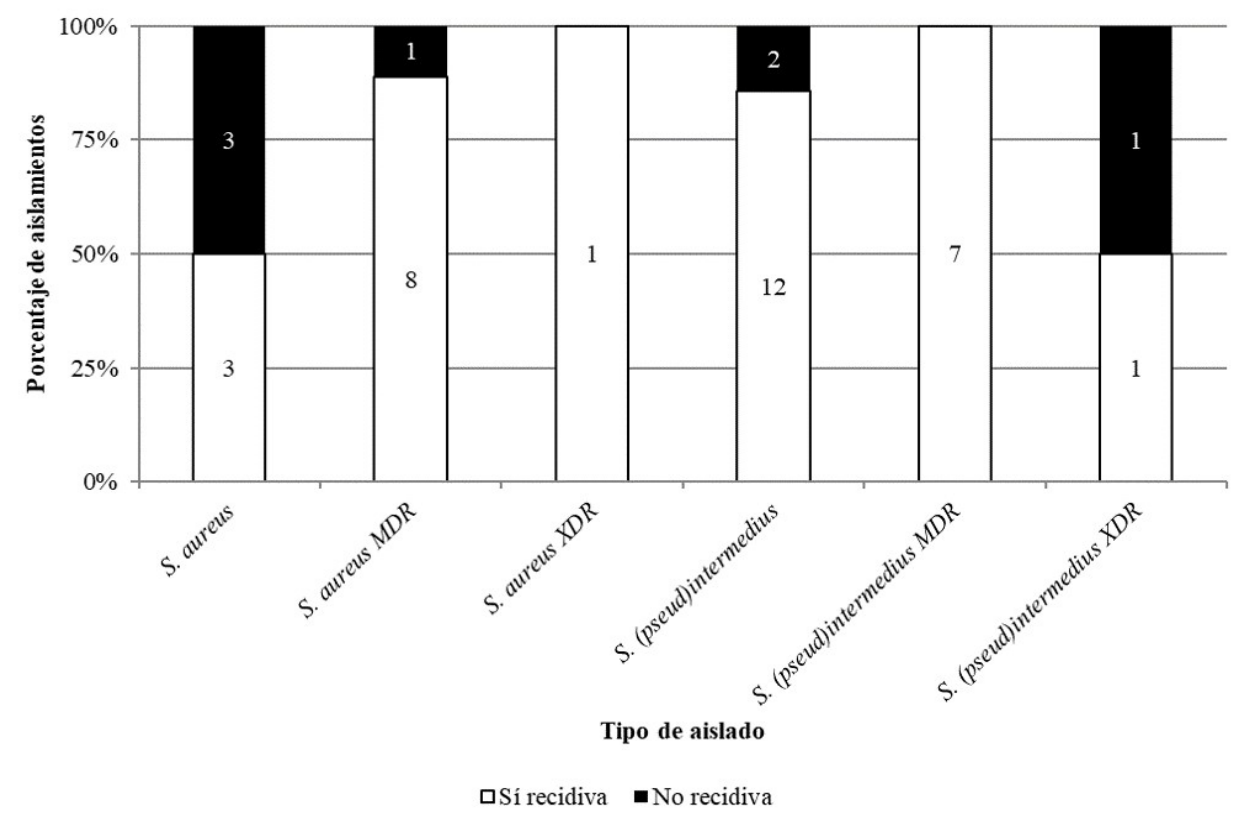

Figura 2. Distribución de frecuencia de los aislados de Staphylococcus (pseud)intermedius y Staphylococcus aureus de acuerdo con el perfil de susceptibilidad antimicrobiana y la condición de recidiva clínica de pioderma de los pacientes. Números dentro de barras indican frecuencias absolutas, eje vertical señala frecuencia relativa. MDR $=$ resistencia múltiple, $X D R=$ resistencia expandida 


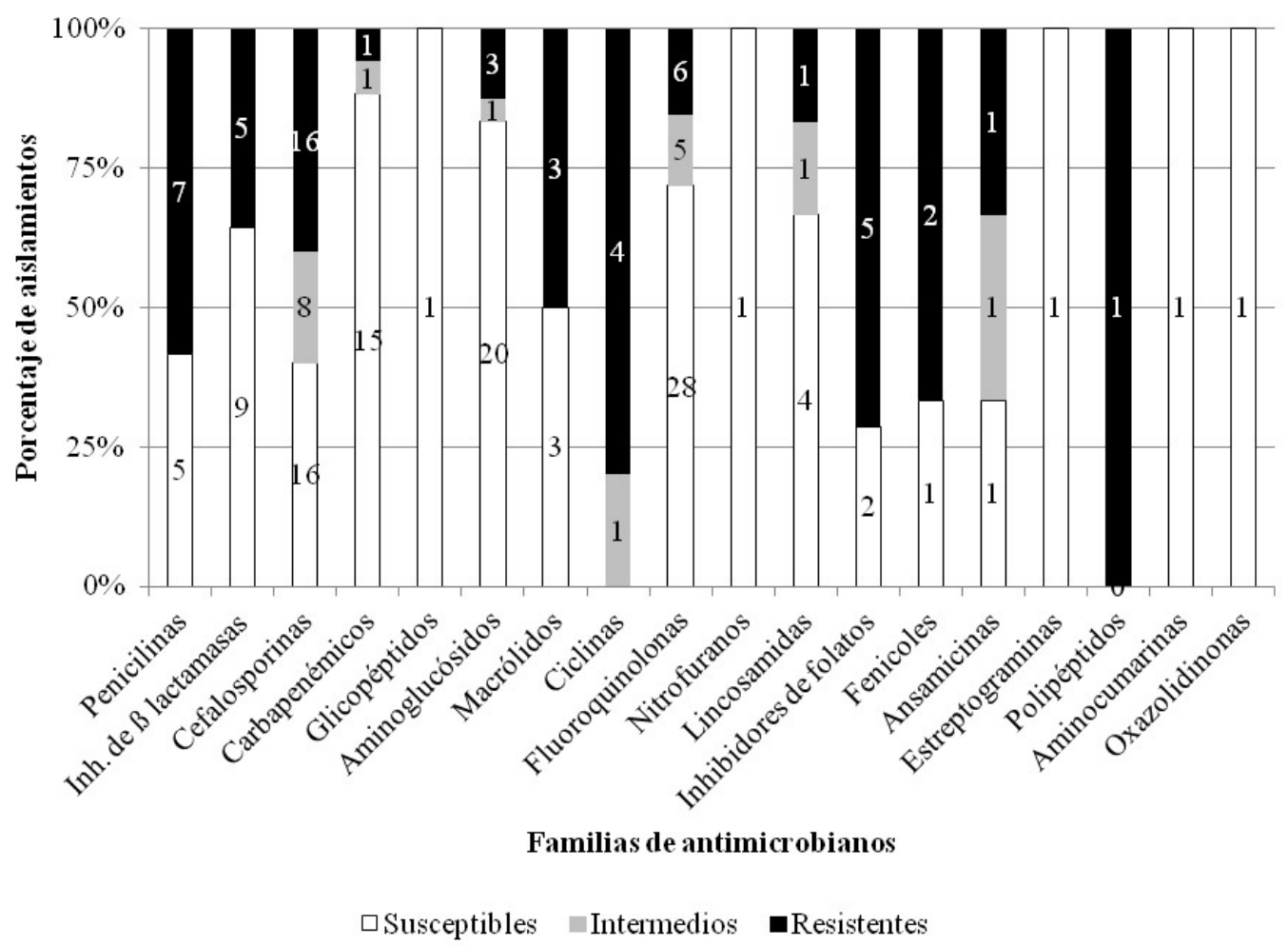

Figura 3. Susceptibilidad de aislados de S. aureus frente a diversas familias de antimicrobianos. Números dentro de barras indican frecuencias absolutas, eje vertical señala frecuencia relativa

jes de susceptibilidad en el resto de los compuestos (Lnz, Nov, Bac, QD, Rif, Clor, Nit, Tei, lincosamidas, fluoroquinolonas, macrólidos y $\beta$-lactámicos/inhibidores de $\beta$ lactamasas).

Se detectaron nueve especímenes de $S$. aureus como MDR (56.2\%), de los cuales ocho presentaron resistencia a Oxa o Cfx y solo una cepa fenotípicamente se predice como negativa a mecA (CLSI, 2011), la cual no mostró susceptibilidad a otros antibióticos (Tet, Cip, SxT y Rif) (Magiorakos et al., 2012). Solo un aislado se categorizó como XDR (6.2\%), el cual también se predice como productor de PBP2 (CLSI, 2011, 2018a) (Figura 2). En estos aislados, de manera concurrente, se consiguió resistencia a antimicrobianos como Azt, Tet, Sxt, Eri, Clin, Bac, Cipro, Clor, Rif y Amk.
No se encontró asociación significativa en los resultados de susceptibilidad o resistencia en los seis aislados restantes (ECN, Staphylococcus spp y $S$. haemolyticus) (Cuadro 3), quizás porque el número de cepas fue reducido o inclusive algunos antibióticos no fueron evaluados. Para estas cepas no se realizaron las clasificaciones en categorías de acuerdo a la multirresistencia, debido a que en la literatura solo hay antecedentes para $S$. aureus (Magiorakos et al., 2012) y $S$. (pseud)intermedius (Worthing et al., 2018), siendo que entre estas dos últimas $(\mathrm{n}=39)$ se obtuvo $25.6 \%(\mathrm{n}=10)$ y $23.1 \%$ $(\mathrm{n}=9)$, respectivamente, de aislados MDR o XDR; sin embargo, al considerar las proporciones dentro de cada taxón, los primeros resultan más frecuentes $(10 / 16,62.5 \%$ vs. 9/23,39.1\%), sin diferencias significativas (Figura 2). 
Cuadro 3. Resultados de ensayos de susceptibilidad antimicrobiana de otros estafilococos ${ }^{\mathrm{a}}$ aislados en casos de pioderma canina

\begin{tabular}{|c|c|c|c|c|c|c|c|c|}
\hline \multirow{2}{*}{$\begin{array}{l}\text { Familia de } \\
\text { antimicrobianos }\end{array}$} & \multicolumn{2}{|c|}{$\begin{array}{l}\text { Staphylococcus } \\
\text { haemolyticus }\end{array}$} & \multicolumn{3}{|c|}{ Staphylococcus spp } & \multicolumn{3}{|c|}{$\begin{array}{c}\text { Estafilococos coagulasa } \\
\text { negativo }\end{array}$} \\
\hline & $\mathrm{S}$ & $\mathrm{R}$ & $\mathrm{S}$ & I & $\mathrm{R}$ & $\mathrm{S}$ & I & $\mathrm{R}$ \\
\hline Penicilinas & & $2(\mathrm{Ox})$ & & & $\begin{array}{c}1 \\
(\mathrm{Ox})\end{array}$ & & & $1(\mathrm{Ox})$ \\
\hline $\begin{array}{l}\text { B-lactámicos / } \\
\text { Inhibidores de } \beta \text { - } \\
\text { lactamasas }\end{array}$ & & & & & & $2(\mathrm{Amc})$ & & \\
\hline Cefalosporinas & & & & & & $\begin{array}{c}3(\mathrm{Cfx}, \\
\text { Cpm, } \\
\text { Cro })+ \\
2(\mathrm{Cxm})\end{array}$ & & $\begin{array}{c}1 \\
(\mathrm{Ctx})\end{array}$ \\
\hline Carbapenémicos & 2 (Imp) & & & & & 1 (Imp) & & \\
\hline Aminoglucósidos & $\begin{array}{l}3 \text { (Gen, Net } \\
\text { y Amk) }\end{array}$ & & $\begin{array}{c}1 \\
(\mathrm{Net})\end{array}$ & & & $\begin{array}{l}2 \text { (Gen) } \\
\quad+2 \\
\text { (Amk) }\end{array}$ & & $\begin{array}{c}1 \\
(\mathrm{Neo})\end{array}$ \\
\hline Ciclinas & 1 (Dox) & & & & $\begin{array}{c}1 \\
\text { (Tet) }\end{array}$ & 1 (Dox) & & \\
\hline Fluoroquinolonas & $\begin{array}{c}2(\mathrm{Cip})+2 \\
\quad(\mathrm{Lom})\end{array}$ & & & $\begin{array}{l}2 \\
\text { (Cip, } \\
\text { Lom) }\end{array}$ & & $\begin{array}{l}3 \text { (Cip, } \\
\text { Lom, } \\
\text { Ofx) }\end{array}$ & $\begin{array}{c}1 \\
\text { (Lom) }\end{array}$ & $\begin{array}{c}1 \\
\text { (Cip) }\end{array}$ \\
\hline Lincosamidas & 2 (Clin) & & & & & 1 (Clin) & & $\begin{array}{c}2 \\
\text { (Clin, } \\
\text { Linc) }\end{array}$ \\
\hline $\begin{array}{l}\text { Inhibidores de } \\
\text { folatos }\end{array}$ & & $\begin{array}{l}2(\mathrm{Sxt}, \\
\text { Trm) }\end{array}$ & & & & $1(\mathrm{Sxt})$ & & $\begin{array}{c}1 \\
(\mathrm{Sxt})\end{array}$ \\
\hline Fenicoles (Clor) & 1 & & & & & 1 & & \\
\hline Ansamicinas (Rif) & 2 & & & & & 1 & & 1 \\
\hline $\begin{array}{l}\text { Estreptograminas } \\
\text { (QD) }\end{array}$ & & & & & & & & \\
\hline Polipéptidos (Bac) & 1 & 1 & & & 1 & 1 & & 1 \\
\hline
\end{tabular}

Según el Cuadro 1, los 45 animales estudiados se distribuyen en 17 razas caninas, con una mayor frecuencia de Poodle $(\mathrm{n}=13$, 28.9\%), Pug Carlino ( $\mathrm{n}=7,15.6 \%$ ), y Pinscher, Husky Siberiano y Bóxer $(n=3,6.7 \%$ para cada una). Al relacionar los grupos raciales y la recidiva clínica, la mayor proporción nuevamente se correspondió con la raza Poodle $(\mathrm{n}=10,27.8 \%)$, seguida del Pug Carlino $(\mathrm{n}=5$, $13.9 \%)$, y en tercer lugar se tiene a la tríada de Husky Siberiano, Bóxer y Pinscher ( $\mathrm{n}=7$, 19.4\%). Sin embargo, no se detectó asociación entre el grupo racial y la incidencia de recidiva de pioderma.

De las 45 muestras en total, el 20\% representa casos de primoinfección $(\mathrm{n}=9)$, $33.3 \%(n=3)$ en machos y $66.7 \%(n=6)$ en hembras. En el caso de las recidivas, $47.2 \%$ fue en machos y $52.8 \%$ en hembras. Tampo- 
Cuadro 4. Reportes en la literatura de susceptibilidad hacia algunos de los antimicrobianos escrutados en esta investigación, frente a $S$. intermedius y $S$. aureus aislados de pioderma en caninos

\begin{tabular}{|c|c|c|c|c|c|c|c|c|c|c|c|c|}
\hline 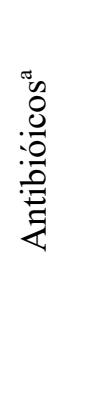 & 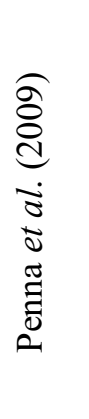 & 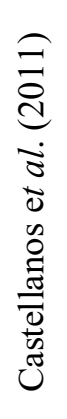 & 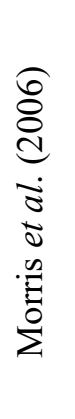 & 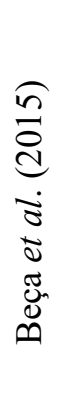 & 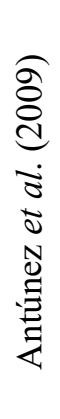 & 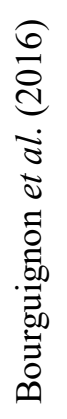 & 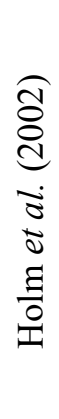 & 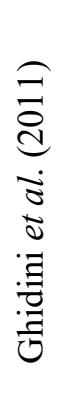 & 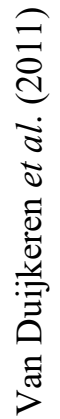 & 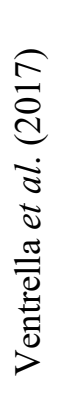 & 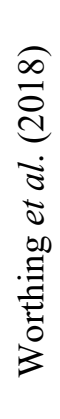 & 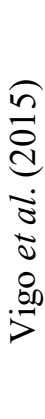 \\
\hline $\mathrm{P}$ & & & & $\mathrm{R}, \mathrm{r}$ & $\mathrm{R}$ & & & & & & & \\
\hline Oxa & $\mathrm{R}$ & & $\mathrm{R}$ & $\mathrm{R}, \mathrm{r}$ & $\mathrm{R}$ & $\mathrm{R}$ & & $\mathrm{R}, \mathrm{r}$ & & $\mathrm{R}$ & $\mathrm{R}$ & $\mathrm{R}$ \\
\hline Amp & & & & $\mathrm{R}, \mathrm{r}$ & $\mathrm{R}$ & & & & & & & \\
\hline $\mathrm{AmC}$ & $\mathrm{R}$ & & & $\mathrm{R}, \mathrm{r}$ & $\mathrm{R}$ & $\mathrm{R}$ & & $\mathrm{R}, \mathrm{r}$ & & & & \\
\hline SAM & $\mathrm{R}$ & & & & & & & & & & & \\
\hline Cef & & & & & $\mathrm{R}$ & & & & & & & \\
\hline Cfx & & & & $\mathrm{r}$ & & & & & & & & \\
\hline $\operatorname{Imp}$ & & & & $\mathrm{S}, \mathrm{s}$ & & $\mathrm{S}$ & & $\mathrm{R}, \mathrm{r}$ & & & & \\
\hline Tei & & & & $\mathrm{S}, \mathrm{s}$ & & & & & & & & \\
\hline $\mathrm{Neo}$ & $\mathrm{R}, \mathrm{r}$ & & $\mathrm{R}, \mathrm{r}$ & $\mathrm{R}$ & $\mathrm{R}$ & & $\mathrm{R}$ & & & & & \\
\hline Gen & $\mathrm{R}, \mathrm{r}$ & $\mathrm{R}$ & $\mathrm{R}, \mathrm{r}$ & $\mathrm{R}, \mathrm{s}$ & $\mathrm{R}$ & & $\mathrm{R}$ & $\mathrm{R}, \mathrm{r}$ & $\mathrm{R}$ & $\mathrm{R}$ & $\mathrm{R}$ & $\mathrm{R}$ \\
\hline Amk & $\mathrm{R}, \mathrm{r}$ & & & & $\mathrm{R}$ & & & $\mathrm{R}, \mathrm{r}$ & & & & \\
\hline Azt & & & & & & $\mathrm{R}$ & & & & & & \\
\hline Eri & $\mathrm{R}, \mathrm{r}$ & $\mathrm{R}$ & $\mathrm{R}, \mathrm{r}$ & $\mathrm{R}, \mathrm{r}$ & $\mathrm{R}$ & & $\mathrm{R}$ & $\mathrm{R}, \mathrm{s}$ & $\mathrm{R}$ & & & $\mathrm{R}$ \\
\hline Tet & & & $\mathrm{R}, \mathrm{r}$ & $\mathrm{R}, \mathrm{r}$ & $\mathrm{R}$ & & $\mathrm{R}$ & & $\mathrm{R}$ & & $\mathrm{R}$ & $\mathrm{R}$ \\
\hline Dox & & $\mathrm{R}$ & & & $\mathrm{R}$ & $\mathrm{R}$ & & $\mathrm{R}, \mathrm{r}$ & & $\mathrm{R}$ & & \\
\hline Cip & $\mathrm{R}$ & & & $\mathrm{R}, \mathrm{r}$ & $\mathrm{R}$ & $\mathrm{R}$ & & $\mathrm{R}, \mathrm{r}$ & $\mathrm{R}$ & $\mathrm{R}$ & $\mathrm{R}$ & $\mathrm{R}$ \\
\hline Lom & & & & $\mathrm{R}, \mathrm{r}$ & & & & & & & & \\
\hline Nor & & & & & $\mathrm{R}$ & & & & & & & \\
\hline Nit & $\mathrm{R}, \mathrm{r}$ & & & $\mathrm{S}, \mathrm{s}$ & & & $\mathrm{R}$ & & & & & $\mathrm{S}$ \\
\hline Clin & & $\mathrm{R}$ & $\mathrm{R}, \mathrm{r}$ & $\mathrm{R}, \mathrm{r}$ & $\mathrm{R}$ & $\mathrm{R}$ & $\mathrm{R}$ & $\mathrm{R}, \mathrm{s}$ & $\mathrm{R}$ & & & $\mathrm{R}$ \\
\hline Linc & & & & & $\mathrm{R}$ & & & $\mathrm{R}, \mathrm{r}$ & & & & \\
\hline SxT & & & $\mathrm{R}, \mathrm{r}$ & $\mathrm{R}, \mathrm{s}$ & $\mathrm{R}$ & & $\mathrm{R}$ & $\mathrm{R}, \mathrm{r}$ & & & $\mathrm{R}$ & $\mathrm{R}$ \\
\hline Trm & & S & & & & & & & $\mathrm{R}$ & & & \\
\hline Clor & $\mathrm{R}, \mathrm{r}$ & $\mathrm{R}$ & $\mathrm{R}, \mathrm{r}$ & $\mathrm{R}, \mathrm{r}$ & $\mathrm{R}$ & & $\mathrm{R}$ & $\mathrm{R}, \mathrm{r}$ & $\mathrm{R}$ & & $\mathrm{R}$ & $\mathrm{R}$ \\
\hline Rif & & & & $\mathrm{R}, \mathrm{s}$ & & & & $\mathrm{R}, \mathrm{r}$ & & & $\mathrm{R}$ & $\mathrm{S}$ \\
\hline QD & & & & $\mathrm{S}, \mathrm{s}$ & & & & & & & & \\
\hline $\mathrm{Bac}$ & $\mathrm{R}, \mathrm{r}$ & & & & & & & & & & & \\
\hline
\end{tabular}

$\mathrm{R}=$ al menos un aislado de $\mathrm{S}$. intermedius con resistencia, $\mathrm{S}=100 \%$ de susceptibilidad en los aislados de $S$. intermedius, $r=$ al menos un aislado de $S$. aureus con resistencia, $s=100 \%$ de susceptibilidad en los aislados de $S$. aureus

a Desde 2016 los aislados de S. (pseud)intermedius resistentes a Oxa se catalogan como SPRM (Wu et al., 2016; CLSI, 2018a), por lo que en resultados previos los correspondientes aislados se deberían considerar como MDR (Magiorakos et al., 2012) 
co se encontró asociación significativa entre el sexo de los pacientes y la incidencia de recidiva de pioderma.

La frecuencia de recidivas fue significativamente mayor $(\mathrm{p}<0.05)$ a partir de la adultez, abarcando el $88.9 \%$ de los casos $(n=32,16$ en adultos y 17 en gerontes), mientras que entre los estratos de individuos con primoinfección no se detectó diferencias entre grupos etarios.

\section{Discusión}

Esta investigación es semejante a otras realizadas en ciudades latinoamericanas como Lima (Antúnez et al., 2009), Río de Janeiro (Penna et al., 2009), Bogotá (Castellanos et al., 2011), Buenos Aires (Vigo et al., 2015) y Minas Gerais (Bourguignon et al., 2016).

La frecuente etiología del pioderma canino por estafilococos puede atribuirse a factores de virulencia propios de las especies coagulasa positivo (ECP) (Antúnez et al., 2009; Futagawa-Saito et al., 2009; Geoghegan et al., 2009; Van Duijkeren et al., 2011). En esta investigación se obtuvieron altos registros de $S$. intermedius, coincidiendo con reportes bajo esta nomenclatura (Abusleme, 2009; Antúnez et al., 2009; Castellanos et al., 2011; Ghidini et al., 2011) o como S. pseudintermedius (Van Duijkeren et al., 2011; Kadlec y Schwarz, 2012; Braga et al., 2015; Bourguignon et al., 2016).

La detección en menor proporción de $S$. aureus también ha sido documentada en investigaciones de pioderma canino (Holm et al., 2002; Duquette y Nuttall, 2004; Antúnez et al., 2009; Beck et al., 2012). En humanos el panorama es diferente (Duquette y Nuttall, 2004; Cain, 2013; Beck et al., 2012; Limbago, 2016), quizás porque esta bacteria presenta mayor afinidad por sus corneocitos en comparación con las células caninas (Simou et al., 2005), para las cuales $S$. (pseud)intermedius presenta mayor atracción, postu- lándose una interacción tipo receptor-ligando (Forsythe et al., 2002), especialmente en animales con antecedentes de dermatitis atópica (McEwan, 2000). No obstante, en esta investigación no se detectó correlación entre la etiología por $S$. (pseud)intermedius y la recidiva, coincidiendo con otros autores (Burkett y Frank, 1998; Holm et al., 2002).

Durante los últimos 15 años se ha expandido el conocimiento de la genética poblacional de $S$. (pseud)intermedius y los perfiles de susceptibilidad antimicrobiana (dos Santos et al., 2016; Ventrella et al., 2017; Staphylococcus pseudintermedius Databases, 2018; Worthing et al., 2018), resaltando la diseminación de algunos grupos clonales multirresistentes, incluyendo cepas SPRM (Beck et al., 2012). Estos fenómenos son de importancia en Salud Pública (Duquette y Nuttall, 2004; Guardabassi et al., 2004; Kelesidis y Tsiodras, 2010; Van Duijkeren et al., 2011), además de las complicaciones añadidas que representan para los tratamientos en clínica veterinaria (Duquette y Nuttall, 2004; Frank y Loeffler, 2012; Kadlec y Schwarz, 2012; Worthing et al., 2018).

\section{S. (pseud)intermedius}

En casi todas las familias se registró al menos un resultado de no susceptibilidad para esta especie (Figura 1). La resistencia a $\beta-$ lactámicos (penicilinas, aminopenicilinas, $\beta$ lactámicos/inhibidores de B-lactamasas y cefalosporinas o cefamicinas (Magiorakos $e t$ al., 2012) (Cuadro 2) ha sido reportada (Cuadro 4), aunque también hay investigadores que han detectado susceptibilidad en general para estos compuestos (Holm et al., 2002; Ganiere et al., 2005).

La resistencia mediada por PBP2 en $S$. (pseud)intermedius puede detectarse putativamente en estudios de susceptibilidad con Oxa, con el cual se predice la presencia de mecA (Kadlec y Schwarz, 2012; Cain, 2013; Wu et al., 2016; CLSI, 2018a); sin embargo, también se ha descrito blaZ en esta 
bacteria, tanto en aislados SPRM como sensibles a la meticilina (SPSM) (Kadlec y Schwarz, 2012).

La frecuencia de resistencia a cefalosporinas, inhibidores de síntesis de folatos y ciclinas es significativamente mayor $(p<0.05)$ respecto al resto de los antibióticos, con probable correlación con los fenómenos de multirresistencia documentados para aislados SPRM (dos Santos et al., 2016; Worthing et al., 2018), por lo que no es recomendable la prescripción de estos compuestos junto con las penicilinas y $\beta$ lactámicos/inhibidores de ß-lactamasas en casos de pioderma en caninos. Si bien para estos dos últimos no se evidenció un incremento en la resistencia, buena parte de los aislados de $S$. (pseud)intermedius de Coro se catalogaron como MDR y XDR.

Respecto a las ciclinas, las cepas de $S$. (pseud)intermedius mostraron resistencia (Figura 1) de manera semejante a otros reportes (Cuadro 4). La baja susceptibilidad se ha correlacionado al menos para bacteria con tet $\mathrm{M}$, tet $\mathrm{K}$, tet $\mathrm{L}$ y tet $\mathrm{O}$, los cuales se pueden presentar solos o en combinación (Kadlec y Schwarz, 2012); sin embargo, el primero es el más frecuente (Kim et al., 2005; Cain, 2013), para el cual se predice resistencia a todos los antibióticos de esta clase (Cain, 2013).

Entre los inhibidores de síntesis de folatos, SxT es el más usado en procesos dermatológicos; sin embargo, para $S$. (pseud)intermedius es frecuente la resistencia, concordando con los registros de esta investigación. Por otra parte, la prescripción de Trm es menor, pero igualmente se han detectado aislados tanto $\mathrm{R}$ como $\mathrm{S}$ (Cuadro 4), coincidiendo el primer caso con los resultados en esta ocasión. Los mecanismos moleculares mediadores de la resistencia a sulfas no han sido determinados para esta bacteria, pero la mayoría de los aislados $\mathrm{R}$ presentan el gen $d f r \mathrm{G}$ en el caso de Trm, el cual fue descrito en $S$. aureus (Kadlec y Schwarz, 2012).
Los aislados de $S$. (pseud)intermedius detectados en Coro mostraron en general susceptibilidad hacia carbapenémicos (Figura 1). Si bien estos presentan semejanzas con los ß-lactámicos, tradicionalmente son considerados como un grupo aparte por su amplio espectro y resistencia a la acción de $\beta$ lactamasas. Su uso está regulado y es desaconsejado en clínica veterinaria (Weese y Van Duijkeren, 2010; OIE, 2012b, 2015a), pero la investigación de su eficacia in vitro es de utilidad para registros epidemiológicos. En esta opotunidad, solo se detectó un aislado resistente, coincidiendo con un hallazgo previo (Ghidini et al., 2011) (Cuadro 4), mientras que en otras publicaciones se reporta susceptibilidad (Beça et al., 2015; Bourguignon et al., 2016).

Se evaluaron Tei, Lnz y QD, para los cuales los aislados de $S$. (pseud)intermedius presentaron $100 \%$ de sensibilidad, coincidiendo con otros autores (Cuadro 4). De manera semejante a lo argumentado para los carbapenémicos, el estudio de susceptibilidad a antibióticos de estas tres clases tiene aplicabilidad en el ámbito investigativo (Weese y Van Duijkeren, 2010; OIE, 2012b).

En el caso de los aislados de $S$. (pseud)intermedius analizados frente a aminoglucósidos, macrólidos y lincosamidas, se obtuvieron porcentajes de no susceptibilidad de 25.7, 37.5 y $33.3 \%$, respectivamente (Figura 1), coincidiendo con múltiples reportes (Cuadro 4). Al respecto, se han detectado genes que confieren resistencia a uno o varios antibióticos dentro de cada familia, tanto en cepas SPRM como SPSM, siendo mecanismos semejantes a los descritos para $S$. aureus (Kadlec y Schwarz, 2012; Cain, 2013).

El uso de las fluoroquinolonas es común en clínica veterinaria; sin embargo, la aplicabilidad de la evaluación de estos compuestos en estafilococos es quizás limitada, pues a los pocos días de inicio de tratamientos in vivo surge resistencia (CLSI, 2018a). En el caso de los aislamientos de $S$. (pseud)intermedius de Coro, se observó 
$73.3 \%$ de susceptibilidad (Figura 1), coincidiendo con algunos investigadores (Cuadro 4). Adicionalmente, se ha descrito resistencia para otros antibióticos de este grupo, como por ejemplo enrofloxacina (Morris et al., 2006: Antúnez et al., 2009; Ghidini et al., 2011; Bourguignon et al., 2016) y marbofloxacina (Ganiere et al., 2005; Morris et al., 2006; Ghidini et al., 2011), los cuales son alternativos para el tratamiento del pioderma canino por $S$. (pseud)intermedius. Su uso es equiparable al del orbifloxacino, para el cual se ha descrito eficacia en tratamientos clínicos (González et al., 2006). Las investigaciones de los mecanismos de resistencia revelan mutaciones puntuales en dominios conservados de las enzimas blanco (Kadlec y Schwarz, 2012), siendo descritas tanto en $S$. (pseud)intermedius como en $S$. aureus (Cain, 2013).

Los nitrofuranos son fármacos recomendados para infecciones urinarias, las cuales no están habitualmente vinculadas con $S$. (pseud)intermedius, pero el estudio de su eficacia tiene aplicabilidad epidemiológica (OIE, 2015c), de esta manera, otros autores también han detectado susceptibilidad como en esta ocasión (Cuadro 4).

Entre los fenicoles, Clor es el compuesto referencial para las evaluaciones de susceptibilidad (Magiorakos et al., 2012; CLSI, 2018a), aunque en el entorno clínico se apliquen análogos (OIE, 2015a). En la investigación efectuada en Coro se obtuvieron aislados R de $S$. (pseud)intermedius, los cuales coincidentemente eran cepas MDR y XDR, encontrándose en la literatura reportes semejantes (Cuadro 4). La mayoría de los casos resistentes están correlacionados con el gen cat (Kim et al., 2005), albergado en variantes más pequeñas de $\mathrm{pC} 221$ (Kadlec y Schwarz, 2012).

La rifampicina debe usarse preferentemente en combinación con otros antimicrobianos (CLSI, 2018a) como estrategia para limitar la aparición de resistencia (Worthing et al., 2018), siendo este fenómeno infrecuente en $S$. (pseud)intermedius, por lo que los mecanismos implicados son poco conocidos (Kadlec y Schwarz, 2012). El único aislado $R$ registrado en este estudio es catalogado como MDR por su no susceptibilidad a SxT y Tet, y aunque no se le evaluó la susceptibilidad a Oxa, la misma probablemente también sea limitada, dado que los pocos aislados descritos en la literatura coincidentemente son SPRM (Kadlec y Schwarz, 2012; Worthing et al., 2018) (Cuadro 4).

La evaluación de la susceptibilidad de estafilococos hacia Bac no está considerada (CLSI, 2018a), ni aun para S. (pseud)intermedius (Magiorakos et al., 2012), pero en esta investigación se realizaron dos ensayos (Figura 1), detectándose en ambos casos resistencia, coincidiendo con investigaciones previas (Penna et al., 2009) (Cuadro 4).

\section{S. aureus}

Se observó susceptibilidad en el 59.7\% de los ensayos realizados (Figura 3 ), pero de manera semejante a lo visto en $S$. (pseud)intermedius, en casi todas las familias se detectó al menos un aislado resistente, llegando a registrarse incluso cepas MDR y XDR. La susceptibilidad fue significativa para aminoglucósidos y carbapenémicos $(p<0.05)$, aun cuando en ambos se detectaron algunos aislados resistentes, coincidiendo de manera general con otras investigaciones (Cuadro 4).

Por otra parte, la resistencia fue significativamente mayor $(\mathrm{p}<0.05)$ para cefalosporinas, penicilinas, inhibidores de síntesis de folatos y ciclinas (Figura 3), la cual ha sido ampliamente documentada en casos de dermatitis en caninos (Cuadro 4). En el caso particular del primer grupo se dispone de descripciones de resistencia a cefovecina (Ghidini et al., 2011), cefadroxilo y cefalexina (Penna et al., 2009; Ghidini et al., 2011), incluyendo SARM (Morris et al., 2006). 
La resistencia a $\beta$-lactámicos en general (incluyendo a $\beta$-lactámicos antiestafilocóccicos o cefamicinas (Magiorakos et al., 2012) también es predecible con la evaluación de Oxa o Cfx (CLSI, 2011, 2018a), y en este estudio también se registraron varias cepas con esta característica. El aislamiento de SARM en piodermas caninos ha sido reportado, incluyendo cepas con multirresistencia hacia otros compuestos (Cain, 2013). La fuente más probable de contagio de estas cepas puede ser la permanencia en ambientes hospitalarios (de humanos o animales) o bien el contacto con animales con antecedentes de tratamientos prolongados con ß-lactámicos. La transmisión de humanos a animales en entornos comunitarios se considera poco frecuente desde el punto de vista epidemiológico (Duquette y Nuttall, 2004; Cain, 2013).

Para el resto de los antibióticos estudiados, también se detectó susceptibilidad, de manera semejante a descripciones previas (Figura 3, Cuadro 4).

\section{Otros Estafilococos}

Existen reportes de susceptibilidad antimicrobiana de otros estafilococos aislados con menor frecuencia, destacando el caso de $S$. haemolyticus, para el cual se ha descrito resistencia a AmC, Amk, Bac, Eri, Gen, Neo, amoxicilina, cefadroxilo, cefalexina y mupirocina (Penna et al., 2009), mientras que los aislados de Coro mostraron en general sensibilidad a múltiples compuestos (Imp, Gen, Amk, Net, Dox, Cip, Lom, Clin, Clor, Rif y Nov) (Cuadro 3).

\section{Pioderma Recurrente}

La recidiva clínica del pioderma es una condición común en dermatología veterinaria y se considera secundaria a otras patologías de base (Bensignor y Germain, 2004; Hensel et al., 2015). En la mayoría de los casos registrados el principal patógeno fue $S$. (pseud)intermedius, pero no se encontró diferencia con la frecuencia de casos por $S$. aureus. Al respecto, diversos autores afirman que la reaparición de la enfermedad está más bien condicionada por el perfil de susceptibilidad antimicrobiana, siendo los aislados multirresistentes los que complicarían la completa resolución, predisponiendo así las recidivas (Holm et al., 2002; Beck et al., 2012). En esta investigación, este tipo de asociación no fue corroborada. Además, se han realizado estudios de infecciones por diferentes cepas de $S$. (pseud)intermedius, comparando la severidad clínica de las lesiones y hasta la producción de toxinas, pero tampoco se han detectado diferencias significativas (Burkett y Frank, 1998).

S. (pseud)intermedius muestra mayor adherencia hacia corneocitos de ciertas regiones anatómicas (dorso, extremidades anteriores, ingle y axilas) de perros Bóxer y Bull Terrier en comparación con otras razas (spaniels y sabuesos) (Forsythe et al., 2002). En este estudio también se investigó la influencia de este rasgo y el sexo respecto a la recurrencia de la enfermedad, pero no se detectó asociación, quizás porque para las razas citadas se contabilizaron pocos ejemplares.

Las recurrencias fueron significativamente más frecuentes a partir de la adultez, reiterando la aparición del pioderma como una secuela de enfermedades de base (Hensel et al., 2015), lo cual se reforzaría aún más si en los procesos infecciosos se involucran bacterias multirresistentes (Cain, 2013).

\section{Aislados Multirresistentes MDR y XDR}

El hallazgo de aislados multirresistentes de $S$. aureus y $S$. (pseud)intermedius en Coro es coincidente con otros reportes (Cuadro 4). Este rasgo es quizás corolario a la movilidad genética horizontal (Duquette y Nuttall, 2004), dado que muchos de los ele- 
mentos previamente descritos en $S$. aureus y $S$. epidermidis están presentes en cepas MDR y XDR de $S$. (pseud)intermedius (Casagrande et al., 2011; dos Santos et al., 2016). Por otra parte, los aislados SPRM han surgido en múltiples ocasiones en diferentes regiones geográficas como complejos clonales (CC) (Cain, 2013) y esta dinámica aún continúa (dos Santos et al., 2016; Worthing et al., 2018).

El estudio de aislados SPRM con MLST (Multi Locus Sequence Typing) ha permitido detectar varias «secuencias tipo» (dos Santos et al., 2016) (ST) y CC (Worthing et al., 2018), en donde globalmente los más frecuentes son CC258, CC71 y CC45, caracterizados por la resistencia hacia antibióticos no $\beta$-lactámicos. Esto coincide fenotípicamente con los hallazgos para las cepas MDR y XDR de $S$. (pseud)intermedius de esta investigación, para las cuales deberán entonces hacerse estudios moleculares y así precisar a cuáles de los ST y CC descritos pertenecen.

\section{Conclusiones}

- Se reafirma a $S$. (pseud)intermedius como el principal agente etiológico del pioderma en caninos, descartándose a su vez la asociación entre esta bacteria y las recidivas clínicas de la enfermedad.

- Los fármacos con mayor probabilidad de éxito al momento de diseñar la antibioticoterapia empírica para los casos de pioderma canino serían los aminoglucósidos y fluoroquinolonas, caso contrario se aplica para penicilinas, ciclinas, inhibidores de síntesis de folatos y polipéptidos.

- En casos de recidiva debe considerarse la especie bacteriana involucrada y su respectivo perfil de susceptibilidad, dada la elevada frecuencia de aislados MDR y XDR, tanto de $S$. (pseud)intermedius como de $S$. aureus.

\section{Literatura Citada}

1. Abusleme F. 2009. Aislamiento y análisis de susceptibilidad antimicrobiana de cepas de Staphylococcus aureus y Staphylococcus intermedius de perros con otitis externa. Tesis de Médico Veterinario. Santiago de Chile: Univ. de Chile. 46 p.

2. Antúnez $O$, Calle $S$, Morales $S$, Falcón N, Pinto C. 2009. Frecuencia de patógenos aislados en casos clínicos de dermatitis bacteriana canina y su susceptibilidad antibiótica. Rev Inv Vet Peru 20: 332-338. doi: 10.15381/rivep.v20i2.635

3. Balzarini M, Gonzalez L, Tablada M, Casanovés F, Di Rienzo JA, Robledo $C W$. 2008. Manual del usuario InfoStat. Córdoba: Brujas. 336 p.

4. Beça N, Bessa L, Mendes Â, Santos J, Leite-Martins L, Matos A, Martins P. 2015. Coagulase-positive Staphylococcus: prevalence and antimicrobial resistance. J Am Anim Hosp Assoc 51: 365-371. doi: 10.5326/JAAHA-MS-6255

5. Beck KM, Waisglass SE, Dick HL, Weese JS. 2012. Prevalence of meticillin-resistant Staphylococcus pseudintermedius (MRPS) from skin and carriage sites of dogs after treatment of their meticillin-resistant or meticillinsensitive staphylococcal pyoderma. Vet Dermatol 23: 69-67. doi: 10.1111/j.13653164.2012.01035.x

6. Bensignor E, Germain PA. 2004. Canine recurrent pyoderma: a multicenter prospective study. Vet Dermatol 15: 42. doi: 10.1111/j.1365-3164.2004.00414_4.x

7. Bourguignon E, Viçosa G, Corsini C, Moreira M, Nero L, Conceição L. 2016. Description of methicillin-resistant Staphylococcus pseudintermedius from canine pyoderma in Minas Gerais state, Brazil. Arq Bras Med Vet Zoo 68: 299-306. doi: 10.1590/1678-4162-8150 
8. Silva MB, Ferreira FA, Garcia LN, Silva-Carvalho MC, Botelho LA, Figueiredo AM, Vieira-da-Motta $O$. 2015. An evaluation of matrix-assisted laser desorption ionization time-of-flight mass spectrometry for the identification of Staphylococcus pseudintermedius isolates from canine infections. J Vet Diagn Invest 27:231-235. doi: 10.1177/ 1040638715573297

9. Burkett G, Frank LA. 1998. Comparison of production of Staphylococcus intermedius exotoxin among clinically normal dogs, atopic dogs with recurrent pyoderma, and dogs with a single episode of pyoderma. J Am Vet Med Assoc 213: 232-234.

10. Cain CL. 2013. Antimicrobial resistance in staphylococci in small animals. Vet Clin N Am-Small 43: 19-40. doi: 10.1016/ j.cvsm.2012.09.003

11. Casagrande P, Bietta A, Coletti M, Marenzoni ML, Scorza V, Passamonti F. 2011. Insertion sequence IS 256 in canine pyoderma isolates of Staphylococcus pseudintermedius associated with antibiotic resistance. Vet Microbiol 157: 376-382. doi: 10.1016/j.vetmic.2011.12.028

12. Castellanos I, Rodríguez G, Santos R. 2011. Aislamiento e identificación bioquímica de microorganismos bacterianos a partir de infecciones de piel en caninos. Rev Med Vet 22: 21-30. doi: 10.19052/mv.556

13. Cerda J, Vera C, Rada G 2013. Odds ratio: aspectos teóricos y prácticos. Rev Med Chile 141: 1329-1335. doi: 10.4067/ S0034-98872013001000014

14. [CLSI] Clinical and Laboratory Standards Institute. 2006a. Performance standards for antimicrobial disk susceptibility tests. Approved standards M2-A9. $9^{\text {th }}$ ed. Wayne, USA: CLSI. 37 p.

15. [CLSI] Clinical and Laboratory Standards Institute. 2006b. Table 2C Zone diameter interpretative standards and equivalent minimal inhibitory concentration (MIC) breakpoints for Staphylococcus spp. In: Performance standards for antimicrobial susceptibility testing. $16^{\text {th }}$ ed.
Informational Supple-ment, M100-S16. Wayne, USA: CLSI. p 44-51.

16. [CLSI] Clinical and Laboratory Standards Institute. 2011. Table 2C. Zone diameter and MIC interpretative standards for Staphylococcus spp. In: Performance standards for antimicrobial susceptibility testing. $21^{\text {th }}$ ed. Informational Supplement, M100-S21. Wayne; USA: CLSI. p 68-83.

17. [CLSI] Clinical and Laboratory Standards Institute. 2018a. Table 2C Zone diameter and MIC breakpoints for Staphylococcus spp. In: M100 Performance standards for antimicrobial susceptibility testing. $28^{\text {th }}$ ed. Wayne, USA: CLSI. p 54-63.

18. [CLSI] Clinical and Laboratory Standards Institute. 2018b. Appendix B. Intrinsic resistance. In: M100 Performance standards for antimicrobial susceptibility testing. $28^{\text {th }}$ ed. Wayne, USA: CLSI. p 210-215.

19. De la Fuente y Orlen. 2002. Género Staphylococcus. En: Manual de microbiología veterinaria. Madrid: McGrawHill Interamericana. p 431-439.

20. Di Rienzo J, Casanovés F, Gonzalez L, Tablada E, Díaz M, Robledo C, Balzarini M. 2005. Análisis de datos categóricos. En: Bioestadística para las ciencias agropecuarias. $6^{\circ}$ ed. Córdoba: Brujas. p. 255-271.

21. dos Santos T, Damborg P, Moodley A, Guardabassi L. 2016. Systematic review on global epidemiology of methicillin-resistant Staphylococcus pseudintermedius: inference of population structure from multilocus sequence typing data. Front Microb 7: 1599. doi: 10.3389/fmicb.2016.01599

22. Duquette RA, Nuttall TJ. 2004. Methicillin-resistant Staphylococcus aureus in dogs and cats: an emerging problem? J Small Anim Pract 45: 591597. doi: 10.1111/j.1748-5827.2004.tb00180.x

23. Forsythe PJ, Hill PB, Thoday KL, Brown J. 2002. Use of computarized image analysis to quantify staphylococcal 
adhesion to canine corneocytes: does breed and body site have any relevance to the pathogenesis of pyoderma? Vet Dermatol 13: 29-36. doi: 10.1046/j.09594493.2001.00269.x

24. Frank LA, Loeffler A. 2012. Meticilin resistant Staphylococcus pseudintermedius: clinical challenge and treatment options. Vet Dermatol 23: 283-291. doi: 10.1111/j.1365-3164.2012.01047.x.

25. Futagawa-Saito K, Makino S, Sunaga F, Kato Y, Sakurai-Komada N, BaThein W, Fukuyasu T. 2009. Identification of first exfoliative toxin in Staphylococcus pseudintermedius. FEMS Microbiol Lett 301: 176-180. doi: 10.1111/j.1574-6968.2009.01823.x

26. Ganiere JP, Medaille C, Mangion G. 2005. Antimicrobial drug susceptibility of Staphylococcus intermedius clinical isolates from canine pyoderma. $\mathrm{J}$ Vet Med B 52: 25-31. doi: 10.1111/j.14390450.2004.00816.x

27. Geoghegan JA, Smith E, Speziale P, Foster T. 2009. Staphylococcus pseudintermedius express surface proteins that closely resemble those from Staphylococcus aureus. Vet Microbiol 138: 345-352. doi: 10.1016/j.vetmic.2009.03.030

28. Ghidini F, Piancastelli C, Taddei S, Gandolfo E, Cavirani S, Cabassi C. 2011. Antibiotic sensitivity of bacterial isolates from cases of canine dermatitis. New Microbiol 34: 403-408.

29. González JL, Bravo V, Peña A, Bernal M. 2006. Eficacia terapéutica del orbifloxacino (Orbaxs) en el tratamiento de la pioderma canina: un estudio clínico abierto. Clin Vet Peq Anim 26: 9-12.

30. Guardabassi L, Damborg P, Stamm I, Kopp P, Broens E, Toutain P. 2017. Diagnostic microbiology in veterinary dermatology: present and future. Vet Dermatol 28:146-e30. doi: 10.1111/ vde. 12414

31. Guardabassi L, Schwarz S, Lloyd D. 2004. Pet animals as reservoirs of antimicrobial-resistant bacteria. J Antimicrob Chemoth 54: 321-332. doi: 10.1093/jac/dkh332
32. Hensel P, Santoro D, Favrot C, Hill P, Griffin C. 2015. Canine atopic dermatitis: detailed guidelines for diagnosis and allergen identification. BMC Vet Res 11: 196. doi: 10.1186/s12917-015-0515-5

33. Hernández R, Fernández C, Baptista P. 2014. Metodología de la investigación. $6^{\circ}$ ed. México DF: McGraw-Hill Interamericana. $632 \mathrm{p}$.

34. Holm BR, Petersson U, Moner A, Bergstrom K, Franklin A, Greko C. 2002. Antimicrobial resistance in staphylococci from canine pyoderma: a prospective study of first-time and recurrent cases in Sweden. Vet Rec 151: 600-605. doi: 10.1136/vr.151.20.600

35. Ihrke P. 2000. Infecciones integumentarias-infecciones bacterianas de la piel. En: Enfermedades infecciosas en perros y gatos. México DF: McGraw-Hill Interamericana. p 595-602.

36. Kadlec K, Schwarz S. 2012. Antimicrobial resistance of Staphylococcus pseudintermedius. Vet Dermatol 23: 276-282. doi: 10.1111/j.1365-3164.2012.01056.x

37. Kelesidis T, Tsiodras S. 2010. Staphylococcus intermedius is not only a zoonotic pathogen, but may also cause skin abscesses in humans after exposure to saliva. Int J Infect Dis 14: 838-841. doi: 10.1016/j.ijid.2010.02.2249

38. Kim TJ, Na YR, Lee JI. 2005. Investigations into the basis of chloramphenicol and tetracycline resistance in Staphylococcus intermedius isolates from cases of pyoderma in dogs. J Vet Med B 52: 119-124. doi: $10.1111 / \mathrm{j} .1439-0450.2005$.00836.x

39. Kloos W, Jorgensen J. 1985. Staphylococci. In: Lennette EH, Balows A, Hausler WJ, Shadomy HJ (eds). Manual of clinical microbiology. $4^{\text {th }}$ ed. Washington, USA: American Society for Microbiology. p 143-153.

40. Koneman E, Allen S, Janda W, Schreckenberger P, Winn W. 1999. Diagnóstico microbiológico, texto y atlas a color. $5^{\circ} \mathrm{ed}$. Buenos Aires: Médica Panamericana. 588 p. 
41. Kwochka K. 1996. Alteraciones de la piel y oídos. Pioderma. En: Birchard S, Sherding R (eds). Manual clínico de pequeñas especies. México: McGraw-Hill Interamericana. p 327-334.

42. Limbago BM. 2016. What's in a name? The impact of accurate Staphylococcus pseudintermedius identification on appropriate antimicrobial susceptibility testing. J Clin Microbiol 54: 516-517. doi: 10.1128/JCM.03091-15

43. MacFaddin J. 1990. Pruebas bioquímicas para la identificación de bacterias de importancia clínica. México DF: Médica Panamericana. 301 p.

44. Magiorakos AP, Srinivasan A, Carey RB, Carmeli Y, Falagas ME, Giske CG, Harbarth S, et al. 2012. Multidrugresistant, extensively drug-resistant and pandrug-resistant bacteria: an international expert proposal for interim standard definitions for acquired resistance. Clin Microbiol Infec 18: 268281. doi: 10.1111/j.1469-0691.2011.03570.x

45. McEwan NA. 2000. Adherence by Staphylococcus intermedius to canine keratinocytes in atopic dermatitis. Res Vet Sci 68: 279-283. doi: 10.1053/ rvsc. 2000.0378

46. Medleau L, Hnilica K. 2007. Dermopatías bacterianas. En: Dermatología de pequeños animales. $2^{\circ}$ ed. Madrid: Elsevier. p 25-61.

47. Morris DO, Rook KA, Shofer FS, Rankn SC. 2006. Screening of Staphylococcus aureus, Staphylococcus intermedius, and Staphylococcus schleiferi isolates obtained from small companion animals for antimicrobial resistance: a retrospective review of 749 isolates (2003-04). Vet Dermatol 17:332-337. doi: 10.1111/j.13653164.2006.00536.x

48. Nesbitt G, Ackerman L. 2001. Enfermedades bacterianas caninas (piodermia). En: Dermatología canina y felina. Diagnóstico y tratamiento. Junín: Intermédica. p 188-210.
49. [OIE] Organización Mundial de Sanidad Animal. 2012a. Armonización de los programas nacionales de vigilancia y seguimiento de la resistencia a los agentes antimicrobianos. [Internet]. Disponible en: http://www.oie.int/fileadmin/ Home/esp/Interna-tiona_Standard_Setting/docs/pdf/E_Update_2012_Chapter-_6_7_Antibioresistance_2_.pdf

50. [OIE] Organización Mundial de Sanidad Animal. 2012b. Métodos de laboratorio para las pruebas de sensibilidad de las bacterias frente a los antimicrobianos. [Internet]. Disponible en: http://www.oie.int/fileadmin/Home/ esp/Health_standards/tahm/ 3.1_M\%C3\%-A9todos_laboratorio.pdf

51. [OIE] Organización Mundial de Sanidad Animal. 2015a. Lista OIE de agentes antimicrobianos importantes para la medicina veterinaria. En: Normas, directrices y resolución de la OIE en materia de resistencia a los antimicrobianos y del uso de agentes antimicrobianos. París: OIE. p 115-134.

52. [OIE] Organización Mundial de Sanidad Animal. 2015b. Métodos de laboratorio para las pruebas de sensibilidad de las bacterias frente a los antimicrobianos. En: Normas, directrices y resolución de la OIE en materia de resistencia a los antimicrobianos y del uso de agentes antimicrobianos. París: OIE. $p$ 93-114.

53. [OIE] Organización Mundial de Sanidad Animal. 2015c. Uso responsable y prudente de agentes antimicrobianos en medicina veterinaria. En: Normas, directrices y resolución de la OIE en materia de resistencia a los antimicrobianos y del uso de agentes antimicrobianos. París: OIE. p 27-44.

54. Ospina CE. 2016. Manual Procedimientos técnicos. Toma de muestras de laboratorio clínico. [Internet]. Disponible en: http://www.esecar-menemiliaospina.gov.co/2015/images/calidad/mapa3/ $8 \% 20$ Apoyo \%-20Diagnostico\%$20 \mathrm{y} \% 20$ Terapeutico/2\%20Subprocesos/ 
$2 \% 20 \mathrm{Laboratorio} \% 20 \mathrm{Clinico} /$ $2 \% 20 \mathrm{Manua-1es/ADT-S} 2 \mathrm{M} 6$ V2Proc_Tecnicos_Toma_-Muestra_Lab.pdf

55. Peacock J, Peacock P. 2011. Crosssectional studies. In: Oxford handbook of medical statistics. Oxford: Oxford University Press. p 32-33.

56. Penna B, Varges $R$, Medeiros L, Martins G, Martins R, Lilenbaum W. 2009. In vitro antimicrobial susceptibility of staphylococci isolated from canine pyoderma in Rio de Janeiro. Braz J Microbiol 40: 490-494. doi: 10.1590/ S1517-83822009000300011

57. Staphylococcus pseudintermedius MLST Databases. 2018. Oxford: University of Oxford [Internet]. Disponible en: https://pubmlst.org/spseudintermedius/

58. Pianta C, de Oliveira S, Bello L, Telles A, da Silva V. 2006. Pioderma estafilocócico: identificação das espécies e sensibilidade aos antimicrobianos. Rev Cienc Agrovet 5: 60-63.

59. Romero R. 2007. Estafilococos. En: Microbiología y parasitología humana. Bases etiológicas de las enfermedades infecciosas y parasitarias. $3^{\circ}$ ed. México DF: Médica Panamericana. p 687-695.

60. Simou C, Hill PB, Forsythe PJ, Thoday $K \boldsymbol{K}$. 2005. Species specificity in the adherence of staphylococci to canine and human corneocytes: a preliminary study. Vet Dermatol 16: 156-161. doi: 10.1111/ j.1365-3164.2005.-00452.x

61. van Duijkeren E, Catry B, Greko C, Moreno MA, Pomba MC, Pyörälä S, Ruzauskas M, et al. 2011. Review on methicillin-resistant Staphylococcus pseudintermedius. J Antimicrob Chemoth 66: 2705-2714. doi: 10.1093/jac/dkr367
62. Ventrella G, Moodley A, Grandolfo E, Parisi A, Corrente M, Buonavoglia D, Guardabassi L. 2017. Frequency, antimicrobial susceptibility and clonal distribution of methicillin-resistant Staphylococcus pseudintermedius in canine clinical samples submitted to a veterinary diagnostic laboratory in Italy: a 3-year retrospective investigation. Vet Microbiol 211: 103-106. doi: 10.1016/ j.vetmic.2017.09.015

63. Vigo G, Giacoboni G, Gagetti P, Pasterán F, Corso A. 2015. Resistencia antimicrobiana y epidemiología molecular de aislamientos de Staphylococcus pseudintermedius de muestras clínicas de caninos. Rev Argent Microbiol 47: 206-211. doi: 10.1016/j.ram.2015.06.002

64. Weese S, Van Duijkeren E. 2010. Methicillin-resistant Staphylococcus aureus and Staphylococcus pseudintermedius in veterinary medicine. Vet Microbiol 140: 418-429. doi: 10.1016/ j.vetmic.2009.01.039

65. Worthing KA, Abraham S, Coombs GW, Pang S, Saputra S, Jordan D, Trott $D$, et al. 2018. Clonal diversity and geographic distribution of methicillinresistant Staphylococcus pseudintermedius from Australian animals: discovery of novel sequence types. Vet Microbiol 213: 58-65. doi: 10.1016/ j.vetmic.2017.11.018

66. Wu MT, Burnham CA, Westblade LF, Dien Bard J, Lawhon SD, Wallace MA, Stanley T, et al. 2016. Evaluation of oxacillin and cefoxitin disk and mic breakpoints for prediction of methicillin resistance in human and veterinary isolates of Staphylococcus intermedius group. J Clin Microbiol 54: 535-542. doi: 10.1128/JCM.02864-15 